\title{
KASTURBA GANDHI NURSING COLLEGE COLLEGE EVENTS
}

CAREER GUIDANCE PROGRAM"Ambassador Training Programme"

IQAC KGNC Unit organized an Ambassador Training Programme (10.09.2014 to 12.09.2014) for the final year B.Sc (N) (VIII batch) students which commenced on 10.09.2014. The training programme began with an inauguration at 9:30am in I floor Lecture Hall, MGMC \& RI. The Sessions continued for three days and the topics included.

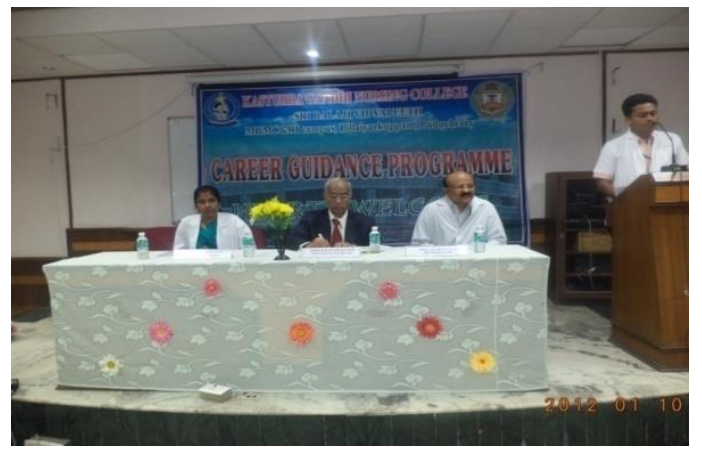

International Career Opportunities, Roles and Responsibilities of Ambulance Nurse, Smart Skill Development In Critical Care Area, Creating an Impression in the Society, Career Opportunities in Gulf Countries, Nursing Career in India, Novice Nurse Expectations of Nurse Leader, Skype interactive session and Personality Development. The students reported that it was useful informative and highly beneficial.

\section{Alumni meet -2014}

KGNC Kasturbians and Research club meet was organized on 25.9.2014. at 1st Floor Lecture Hall, MGMC\&RI. The congregation was welcomed by Ms. K. Ruma Shanthini, President, Kasturbians Society. Mr. R. Vijayaraj, Secretary detailed the activities carried out by the association from inauguration to till date. Financial summary was given by
Ms. Arunadevi, Treasurer. Felicitations were given by Prof. P. Sumathy, HOD, Dept. of Paediatrics, and Prof. Annie Annal, HOD, Dept of OBGY. Followed by presentation on "Right solution for transgender through research possibilities" by Ms. K. Sheethal, SCOHD Society President, Cuddalore who was the special invitee of the day.

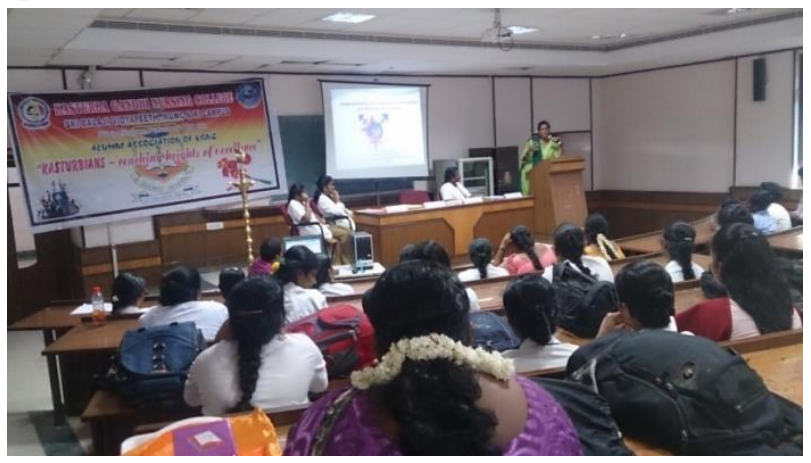

She explained the transgenders issues like social, economical, health and legal issues faced in India. She motivated the Research club of KGNC to take up small projects on the above issues. Special message was given by Prof. K. Renuka, Patron/Principal, KGNC. She addressed the gathering stating the importance of the Alumni Association \& insisted all the alumni members to participate in alumni meet, office bearers election and to conduct conference/workshops by the kasturbians society. She emphasized the fresh alumni members to join the official website and to keep updating their information about placement, Personal information's etc. Vote of thanks was given by Ms. J. Jayasakthi Prabavathy, Vice President of the Kasturbians Society.

\section{REPORT ON REPRODUCTIVE HEALTH} UNIT

Our honorable Vice Chancellor Prof. K. R. Sethuraman inaugurated the Reproductive 
Health Unit by cutting the ribbon and applauded by the dignitaries. The moments were cherished by the distribution of candies which was followed by lighting of the Kuthuvilakku by the dignitaries namely Prof. K. R. Sethuraman Vice Chancellor, SBV, Dr. N. Ananthakrishnan, Dean, Research and PG Studies Dr. S. Krishnan Dean Administration MGMC\&RI and Dr. Seethesh Gosh HOD Department of OBG MGMC\&RI. A small pooja was performed to seek the blessings from the Lord Almighty. The unit comprised of pamphlets on various topics, posters and boards that conveyed information's related to antenatal care, Postnatal Care, breast feeding, Cancer cervix etc. A register has been opened and the members of this unit, has planned for various activities like Health Education, Counselling services, Assessment etc, on a daily basis

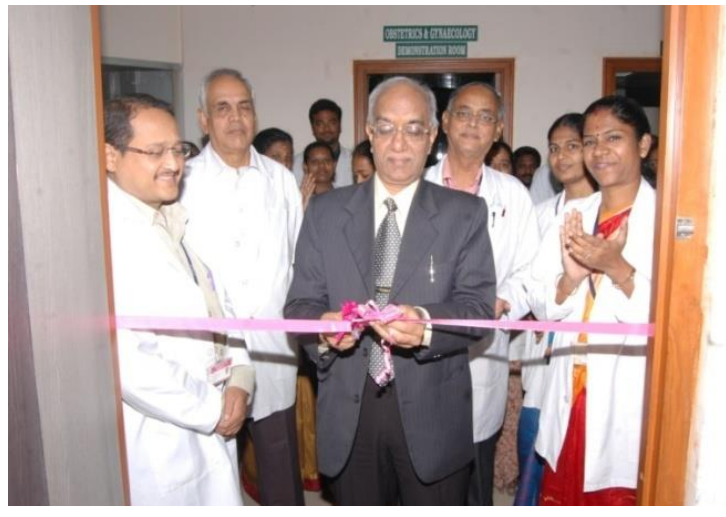

\section{Freshers party report}

The freshers party (gratus 2014) was celebrated on $25 / 10 / 14$ in I st floor Lecture hall, KGNC. The programme commenced by welcoming the freshers by their seniors and children from baby sarah home who presented a card for them. The programme was further highlighted by the culturals organized by B.sc (N) I yr, II yr and IV yr students. The Ryzentronzs B.sc (N) II st yr, requested their juniors for self introduction and to reveal their hidden talents. This gave an opportunity for them to wave off their stage fear. The children from Baby Sarah Home also took part in the culturals. A sum of Rs. 5000/was given as a token of love to the Baby Sarah home by the B.Sc.(N) II yr students which was a memorable event of the celebration and they were also given a memento each. Our Principal Prof. Renuka K greatly appreciated the organizing batch for their untiring efforts in organizing this wonderful celebration after a long period in the history of KGNC which turned to be a great successful event.

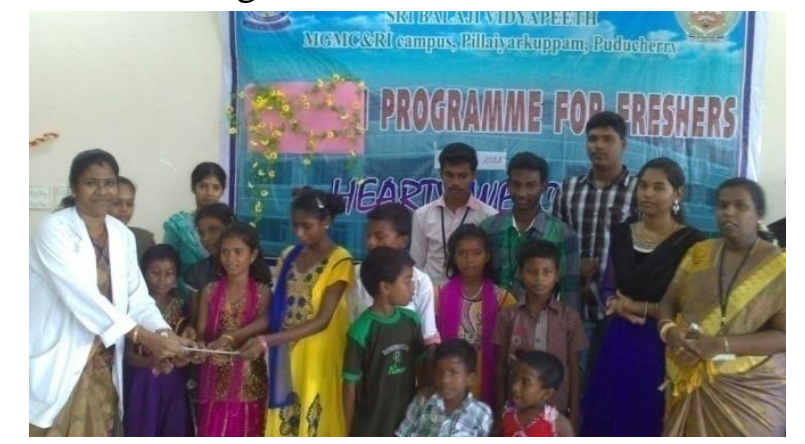

WORLD DIABETIC DAY

The World Diabetes Day was commemorated on 14.11.14. The Department Of Medical Surgical Nursing, KGNC joined hands with the Department Of General Medicine, MGMC \& RI to organize an Awareness programme and Human puppet show by B.Sc(N) II year students on the theme "Prevention Of Type I Diabetes Among Young Adults" The puppet show caught the attention of the public which was evident by their discussion with other people in the MRD and wards regarding the message conveyed in puppet show.

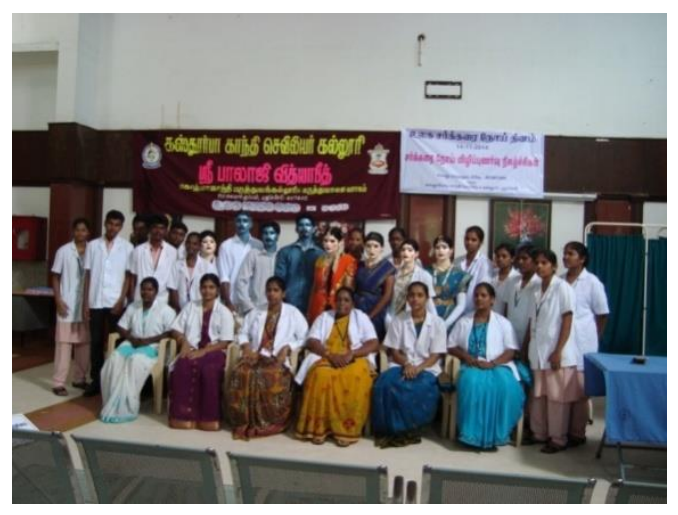

